Pirzada, Non-Human Primates In Research, Voices in Bioethics, Vol. 8 (2022)

\title{
The Ethical Dilemma of Non-Human Primate Use in Biomedical Research
}

\author{
Nefes Pirzada*
}

Keywords: Non-Human Primates, Research Ethics, Animal Autonomy, Regulations, Policies, IACUC, IRB

\section{INTRODUCTION}

When people think of biomedical research, they often envision rats kept in cages with scientists in white coats and blue gloves checking on them, taking notes, and injecting them with substances. The images make some people uncomfortable, evoking a twinge of guilt as they think of the rats suffering. However, the idea that the sacrifice of a few mice saves thousands of human lives may outweigh their guilty conscience. Based on arguments for and against non-human primate (NHP) use in research, this paper concludes that NHP use is scientifically necessary but would be more ethically sound if novel policies and regulations were added to existing measures.

I. Arguments that the Use of NHPs is Ethically Unjustified

On one end of the spectrum, bioethicist Peter Singer argues that animals, including rats, should not be used in biomedical research at all. ${ }^{1}$ He states that the use of animals is an indicator of speciesism. ${ }^{2}$ Like racism, speciesism condemns exploiting a group, here, animals. Singer also challenges differentiating humans and animals based on sentience. He claims that if sentience, autonomy, and self-consciousness provided the basis to deprive animals of the same rights and privileges as humans, then humans who lack such traits would, theoretically, not be entitled to the rights and privileges that other humans have. ${ }^{3}$ Lastly, Singer argues that using animals in experimentation forces researchers to acknowledge similarities between animals and humans. ${ }^{4}$ If a human were to be largely stressed by an experiment, it may be safe to assume that animals, such as rats, would be as well.

Beyond Singer, other authors suggest that it may be ethically impermissible to use NHPs as animal models in biomedical research. They emphasize NHPs' phylogenetic similarities to humans and their need for more

* Nefes Pirzada, Candidate, MS, Columbia University

(C) 2022 Nefes Pirzada. This is an open access article distributed under the terms of the Creative Commons Attribution License, which permits unrestricted use, distribution, and reproduction, provided the original author and source are credited. 
complex social, behavioral, and psychological care in a laboratory environment. ${ }^{5}$ It is difficult to meet these needs, as researchers do not have the resources or the time to devote to consistently fulfilling them. ${ }^{6}$ In addition, NHP use in the US compromises the integrity of the animal model itself. Most NHPs are imported from Asia, Africa, and South America as ${ }^{7}$ there are relatively few captive breeding sites in the US. ${ }^{8}$ These journeys are long and tedious, causing considerable stress on the animal. ${ }^{9}$ Housing conditions, weaning, and quarantine practices further jeopardize animal welfare. ${ }^{10}$ Climate change, new patterns in light-dark cycles, and different diets can alter the physical and social integrity of the NHP. ${ }^{11}$

Some argue that NHPs should not be used in research due to their long lifespan. NHPs can be used for multiple experiments throughout their lifespan. ${ }^{12}$ This can be physically and emotionally taxing on the animals, who would spend years in captivity. ${ }^{13}$ Subjecting NHPs to multiple experiments inflicting varying levels of harm can be seen as a form of abuse. Forcing these highly social and complex animals to live in captivity their whole life, often in inadequate living environments that do not satisfy their complex needs, can result in immense suffering. As anti-vivisection and animal welfare organizations argue, the close phylogenetic similarity of NHPs to humans highlights that they suffer in similar ways to humans. ${ }^{14}$ NHPs respond to pain, and they reflect upon pain as well. ${ }^{15}$ Painful memories endure after experimentation, magnifying the suffering of the animal. ${ }^{16}$ NHPs also exhibit a level of sentience comparable to humans. This challenges Cohen's belief that animals have no rights since NHPs theoretically exercise and respond to moral claims to a certain degree. ${ }^{17} \mathrm{NHPs}$ demonstrate reflective self-awareness, a rudimentary theory of mind, linguistic abilities, and deep emotional attachments. ${ }^{18}$ Given their cognitive complexity and sociality, some would argue that the benefits to the NHP should also be taken into account. NHP use in research rarely, if ever, benefits the NHP. For an animal that expresses a level of sentience, NFT use violates the research principles of autonomy and beneficence.

\section{Arguments Favoring Ethical Use}

On the other end of the spectrum, bioethicist Carl Cohen argues that animals have no rights and research should freely use them. ${ }^{19}$ Cohen claims that animals are incapable of exercising, or responding to, moral claims. ${ }^{20}$ Thus, they cannot engage in free moral judgment. He notes that humans kill millions of animals daily for consumption, despite scientific advancements that have made animal consumption largely unnecessary. Thus, humans kill and consume animals purely for taste and pleasure in the modern day. Cohen questions why it would be ethically permissible to recreationally kill animals without benefit but impermissible to use animals to serve medical science and human advancement. ${ }^{21}$ If the rats in cages were to be altered and a dog was in the place of the rat, more would object to Cohen's utilitarian idea. As dogs are social beings that form bonds with humans, their suffering to save human lives evokes different emotional reactions and is ethically problematic. The closer the bond between an animal and humans, the more unethical their research use seems to be. The ethical implications of animal use reach a pinnacle when the previous example uses a monkey. NHPs are the closest phylogenetic relatives of humans. ${ }^{22}$ NHPs exhibit high levels of intelligence, reflective self-awareness, self-recognition, linguistic abilities, and distinct personalities. ${ }^{23}$ Similar to humans, NHPs create social mechanisms in which they transmit learned behaviors and customs. ${ }^{24} \mathrm{NHPs}$ have proven valuable in the advancement of science and medicine. Approximately 100,000 to 200,000 NHP's are used annually for research worldwide. ${ }^{25}$ The use of NHPs has been rising due to increasing research on monoclonal antibodies, in which NHP's are the only animal that can be used for preclinical safety studies. ${ }^{26}$ 


\section{The Middle of the Spectrum: Permissible Use}

This paper argues that using NHPs as animal models in biomedical research is ethically permissible. NHPs are very phylogenetically similar to humans, making them the ideal models to represent humans in biomedicine. ${ }^{27}$ The Weatherall Report, published in 2006, argues that the use of NHPs in research is "not only morally accepted, but morally required." 28 However, the Report specifies that this argument is credible only if there are no more effective ways of pursuing the research in question. ${ }^{29}$ The report outlines a utilitarian approach to the need for NHPs in research. ${ }^{30}$ The report claims that, while NHPs are harmed in research, the harm is necessary to prevent harm to humans. ${ }^{31}$ While relatively few NHPs are used in research, the number of humans that benefit from the harm decreases the net harm under a utilitarian approach. ${ }^{32}$ Given an NHP's long lifespan and ability to learn social tasks, ${ }^{33}$ an NHP may be used for one study in which it learns a specific skill, then used in subsequent studies that require demonstration of the skill, ${ }^{34}$ resulting in the sacrifice of fewer animals for medical research.

The similarity of NHPs to humans both socially and cognitively may increase better animal welfare practices in the laboratory and a net reduction in harm to animal models in general. For example, positive reinforcement rather than physical restraint can be used with NHPs, encouraging researchers to treat NHPs with more respect than other animals. ${ }^{35}$ Exposure to signs of suffering may lead researchers to adopt research practices that are more humane and minimize the harm to animals. ${ }^{36}$ To be ethical, scientists must consider the importance of the research and the inability to use other animals. If the research can be performed another way, the use of NHPs would not be morally justified. Despite the ethical dilemmas, utilitarianism is the best approach to animal research. NHPs' expressing a cognitive and emotional complexity does not outweigh the benefit to humans as animal models in research. As with the rules surrounding human research subjects, research using NHPs requires protection of the research subjects and requires attention to the scientific benefits.

Current policies guided by Russell and Burch's "3 R's Principle" reduce the harm to NHPs. ${ }^{37}$ The Principle states that in research, there should be a "replacement of animals with non-animal methods;" "reduction of the number of animals used to obtain information of a given amount and precision;" and "refinement of scientific procedures and husbandry to minimize suffering and improve animal welfare." 38 A stringent set of rules and regulations govern NHP use. ${ }^{39}$ The 2000 Chimpanzee Health Improvement, Maintenance, and Protection Act legally prohibits the euthanasia of chimpanzees used in biomedical research. ${ }^{40}$ The Act mandates the creation of sanctuaries where chimpanzees can be retired and cared for until their death. ${ }^{41}$ Institutional Animal Care and Use Committees (IACUCS) regulate the use of NHPs and serve as ethical regulatory committees similar to Institutional Review Boards (IRB) overseeing human subjects research. ${ }^{42}$ IACUCs prohibit academic or commercial research on NHPs unless researchers are appropriately trained, procedures for independent oversight are established, use of the specific species is justified, and the data's significance is established. ${ }^{43}$ The United Kingdom American Society for the Prevention of Cruelty to Animals (ASPCA) has stated that NFT use can occur only if other species are unsuitable for reaching scientific gains. ${ }^{44}$ 45

\section{Recommendations}

While the above policies build a strong foundation to ensure that the research setting ethically respects NPHs, more can be done. Limiting continuous research on one NFT and limiting the number of studies an NHP can participate in would protect the NFT and could consider the level of harm an NHP is exposed to per study. To meet the complex needs of NFTs, animal research labs should be created for NHP use only and should include comprehensive care and specialized captivity practices. ${ }^{46} \mathrm{~A}$ ranking system for labs 
could help distinguish which labs have enough protective measures and a complex environment to be entitled to engage in NHP research. Similar to biosafety levels (BSL) from one to four for research labs, with each level requiring unique sets of protective measures, animal research labs should be created for NHP use that requires the implementation of specific captivity practices.

\section{CONCLUSION}

NHPs have contributed greatly to the scientific community and the advancement of modern medicine. As emotionally and cognitively sophisticated beings, they need special protections in research contexts. As utilitarianism calls for their continued use to save human lives, improving their care in captivity is important to ethical research practices. Policies similar to those regulating human subjects in research should be implemented to protect them. This paper, therefore, sought to offer novel solutions, such as creating a ranking system for animal research laboratories and limiting the number of studies in which an animal can be used.

\footnotetext{
${ }^{1}$ Singer, Peter. "Equality for Animals?" In Practical ethics. Cambridge University Press, 2011.

2 Singer, "Equality for Animals?"

3 Singer, "Equality for Animals?"

4 Singer, "Equality for Animals?"

5 Prescott, Mark J. "Ethics of primate use." Advances in Science and Research 5, no. 1 (2010): 11-22. https://doi.org/10.5194/asr$\underline{5-11-2010}$

${ }^{6}$ Tardif, Suzette D., Kristine Coleman, Theodore R. Hobbs, and Corrine Lutz. "IACUC review of nonhuman primate research." ILAR journal 54, no. 2 (2013): 234-245. https://doi.org/10.1093/ilar/ilt040

7 Prescott, Mark J. "Ethics of primate use." Advances in Science and Research 5, no. 1 (2010): 11-22. https://doi.org/10.5194/asr$\underline{5-11-2010}$

8 Prescott, "Ethics of primate use." 11-22

9 Prescott, "Ethics of primate use." 11-22

10 Prescott, "Ethics of primate use." 11-22

${ }^{11}$ Carlsson, Hans-Erik, Steven J. Schapiro, Idle Farah, and Jann Hau. "Use of Primates In Research: A Global Overview." American Journal of Primatology: Official Journal of the American Society of Primatologists 63, no. 4 (2004): 225-237.

https://doi.org/10.1002/ajp.20054

12 Prescott, "Ethics of primate use." 11-22

13 Prescott, "Ethics of primate use." 11-22

14 Prescott, "Ethics of primate use." 11-22

15 Prescott, "Ethics of primate use." 11-22

16 Prescott, "Ethics of primate use." 11-22

17 Cohen, Carl. "The case for the use of animals in biomedical research." (1986).

https://www.wellbeingintlstudiesrepository.org/cgi/viewcontent.cgi?article=1001\&context=moreaexp

18 Prescott, Mark J. "Ethics of primate use." Advances in science and research 5, no. 1 (2010): 11-22. https://doi.org/10.5194/asr$\underline{5-11-2010}$

${ }_{19}$ Cohen, Carl. "The case for the use of animals in biomedical research." (1986).

https://www.wellbeingintlstudiesrepository.org/cgi/viewcontent.cgi?article=1001\&context=moreaexp

${ }^{20}$ Cohen, "The case for the use of animals in biomedical research."

${ }^{21}$ Cohen, "The case for the use of animals in biomedical research."

22 Tardif, Suzette D., Kristine Coleman, Theodore R. Hobbs, and Corrine Lutz. "IACUC review of nonhuman primate research." ILAR journal 54, no. 2 (2013): 234-245. https://doi.org/10.1093/ilar/ilt040

23 Prescott, Mark J. "Ethics of primate use." Advances in science and research 5, no. 1 (2010): 11-22. https://doi.org/10.5194/asr$\underline{5-11-2010}$

24 Prescott, "Ethics of primate use." 11-22

27 Tardif, Suzette D., Kristine Coleman, Theodore R. Hobbs, and Corrine Lutz. "IACUC review of nonhuman primate research." ILAR journal 54, no. 2 (2013): 234-245. https://doi.org/10.1093/ilar/ilt040
} 
${ }^{28}$ Gardar, "The ethical justification for the use of non-human primates in research." 328-331

${ }^{29}$ Gardar, "The ethical justification for the use of non-human primates in research." 328-331

${ }^{30} \mathrm{Gardar}$, "The ethical justification for the use of non-human primates in research." 328-331

31 Gardar, "The ethical justification for the use of non-human primates in research." 328-331

32 Gardar, "The ethical justification for the use of non-human primates in research." 328-331

33 Tardif, Suzette D., Kristine Coleman, Theodore R. Hobbs, and Corrine Lutz. "IACUC review of nonhuman primate research." ILAR journal 54, no. 2 (2013): 234-245. https://doi.org/10.1093/ilar/ilt040

34 Tardif et al., "IACUC review of nonhuman primate research." 234-235

35 Olsson, I. Anna S., and Peter Sandøe. "“What's wrong with my monkey?" Ethical perspectives on germline transgenesis in marmosets." Transgenic research 19, no. 2 (2010): 181-186. https://doi.org/10.1007/s11248-009-9316-6

${ }^{36}$ Olsson et al., "What's wrong with my monkey?"

37 Prescott, "Ethics of primate use." 11-22

38 Prescott, "Ethics of primate use." 11-22

39 Phillips, Kimberley A., Karen L. Bales, John P. Capitanio, Alan Conley, Paul W. Czoty, Bert A. 't Hart, William D. Hopkins et al. "Why primate models matter." American journal of primatology76, no. 9 (2014): 801-827. https://doi.org/10.1002/ajp.22281

${ }^{40}$ Carlsson, Hans-Erik, Steven J. Schapiro, Idle Farah, and Jann Hau. "Use of primates in research: a global overview." American Journal of Primatology: Official Journal of the American Society of Primatologists 63, no. 4 (2004): 225-237.

https://doi.org/10.1002/ajp.20054

41 Prescott, Mark J. "Ethics of primate use." Advances in Science and Research 5, no. 1 (2010): 11-22. https://doi.org/10.5194/asr$\underline{5-11-2010}$

42 Tardif, Suzette D., Kristine Coleman, Theodore R. Hobbs, and Corrine Lutz. "IACUC Review of Nonhuman Primate Research." ILAR Journal 54, no. 2 (2013): 234-245. https://doi.org/10.1093/ilar/ilt040

43 Phillips, Kimberley A., Karen L. Bales, John P. Capitanio, Alan Conley, Paul W. Czoty, Bert A. 't Hart, William D. Hopkins et al. "Why primate models matter." American journal of primatology76, no. 9 (2014): 801-827. https://doi.org/10.1002/ajp.22281 44 Prescott, Mark J. "Ethics of primate use." Advances in Science and Research 5, no. 1 (2010): 11-22. https://doi.org/10.5194/asr$\underline{5-11-2010}$

${ }^{45}$ Article 7 of Directive 86/609/EEC in the European Commission on the Protection of Animals Used for Experimental and Other Scientific Purposes states that "in a choice between experiments, those which use the minimum number of animals, involve animals with the lowest degree of neurophysiological sensitivity, cause the least pain, suffering, distress, or lasting harm, and which are most likely to provide satisfactory results, shall be selected."

46 Tardif, Suzette D., Kristine Coleman, Theodore R. Hobbs, and Corrine Lutz. "IACUC review of nonhuman primate research." ILAR journal 54, no. 2 (2013): 234-245. https://doi.org/10.1093/ilar/ilt040 